\title{
Operational monitoring of floodplain vegetation using remote sensing
}

\author{
Gertjan Geerling ${ }^{1}$, Ellis Penning ${ }^{1}$, Christine Rogers ${ }^{1}$, Cindy van de Vries - Safavi Nic ${ }^{1}$, \\ Valesca Harezlak ${ }^{1}$, Stanford Wilson ${ }^{1}$, and Gennadii Donchyts ${ }^{1}$ \\ ${ }^{1}$ Affiliation not available
}

June 21, 2021

Gertjan Geerling ${ }^{1,3}$, Ellis Penning ${ }^{1}$, Christine Rogers ${ }^{1}$, Cindy van de Vries - Safavi Nic ${ }^{1}$, Valesca Harezlak ${ }^{1}$, Stanford Wilson ${ }^{2}$, Gennadii Donchyts ${ }^{1}$

${ }^{1}$ Deltares, Delft, The Netherlands

${ }^{2}$ Rijkswaterstaat-WVL, Lelystad, the Netherlands

${ }^{3}$ Deptartment of Environmental Science, Radboud University, Nijmegen, the Netherlands

Corresponding author: Gertjan Geerling email: gertjan.geerling@deltares.nl

\section{Acknowledgements}

This research was funded by the research programme of the Dutch National Water Authority (KPP-Corporate Innovation Programme and the KPP- Innovative Monitoring). We thank the valuable discussions with the Floodplain Management Team of the National Water Authority (RWS-ON) and all other contributing stakeholders.

\begin{abstract}
In deltas, rivers are often embanked and have a limited discharge capacity. In case these rivers also have a fixed riverbed for navigation, vegetation succession in the floodplains will reach climax stages. This leads to increasing hydraulic roughness that lowers the discharge capacity and prompts the river manager to intervene in the floodplain vegetation. The Dutch river manager depended on a 6-year map cycle of manually digitized aerial photographs for assessment of the state of hydraulic resistance. As the amount of agriculture in floodplains is receding in favor of nature rehabilitation projects, the vegetation dynamics increase. At the same time, the bigger floods were anticipated in the future. Therefore, more up-to-date floodplain vegetation maps with a short processing time were needed for about $500 \mathrm{kms}$ of river in the Netherlands. We present an operational web-based monitoring tool that analyses sentinel-2 data on the fly though Google Earth Engine to provide an overview of the current state of the vegetation in the entire floodplain area of the Dutch river systems Rhine and Meuse. It is the first satellite-based application in an operational setting for the Dutch National River Manager (Rijkswaterstaat). The tool compares a map of allowable vegetation with the remotely sensed current situation for a quick scan of hotspots and can create reports on the cadastral (landowner) level. We describe the results of the image classifications and the role of this tool in the full process of the Dutch flood risk management process.
\end{abstract}


Keywords: river management, vegetation, vegetation succession, remote sensing, open data, google earth engine

\section{Introduction}

Floodplain vegetation is intrinsically dynamic due to the nature of the rivers hydrology and resulting morphological changes in interaction with vegetation during high flows. When rivers can freely move along with their dynamic discharge patterns, also patterns of vegetation dynamics can be observed . During high flow vegetation patches may be removed by the water and new bare sandbars may appear where vegetation growth recommences. However, in trained rivers where levees and groynes limit the movement of the river and dams regulate the discharge, vegetation is normally not set back in a natural manner, resulting in a steady increase in the amount of vegetation, mainly floodplain forests .

In embanked rivers with a limited discharge capacity, the overall hydraulic roughness of vegetation in the floodplains determines flood levels. Over the last fifty years two observed developments have increased the need for a good understanding of the developments of floodplain vegetation: (1) A shift from agriculture as the dominant land-use in the floodplain to a synergy between increase in discharge capacity and a trend for nature rehabilitation that has led to more dynamic floodplain vegetation patterns in space and time. An example is the change shown in Figure 1. (2) Higher flood forecasts have led to the need for a stricter management of margins of cultivated areas and unmanaged natural government properties. As a result of these two developments the floodplain vegetation has become more dynamic and increased the nature vs floods dilemma. This has led to proposed strategies like room for the river (Klijn et al 2018) and cyclic rejuvenation (Baptist et al 2004).

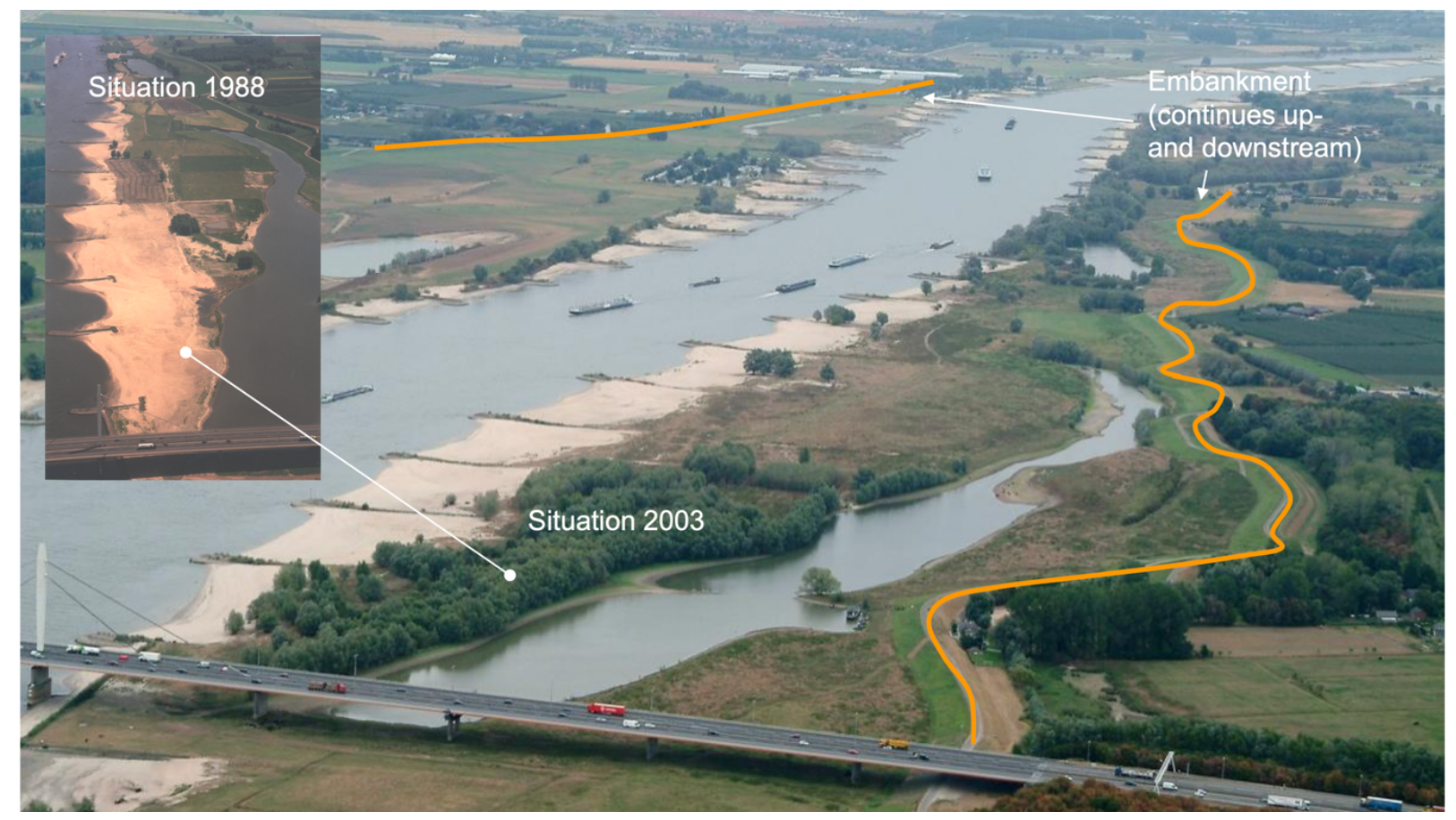

Figure 1: Vegetation development in embanked floodplains. Embankments indicated in orange. The embankment continues up- and downstream. On excavated soils pioneer forest settles and affects the discharge capacity along the Waal River (NL), one of the Dutch Rhine Branches. Coordinates $51.88^{\circ} \mathrm{N}, 5.74^{\circ} \mathrm{E}$ (Photo source: RWS, 2003; Geerling et al., 2008). 
The Dutch Rhine and Meuse rivers are such examples and are strictly managed to ensure that the hydraulic roughness in the embanked floodplains will not increase water levels during a flooding. The Dutch floodplains consist roughly of $30 \%$ intense agricultural use, $26 \%$ natural grassland, $23 \%$ open water, $5 \%$ bare or built, $6 \%$ forest \& bush . Vegetation management consists of small-scale management such as mowing, grazing or harvesting of woody vegetation. Natural parts of the floodplains are often extensively grazed by cattle and wild horses to slow ecological succession, while agricultural areas are managed more intensively through harvesting and mowing. Quickly developing pioneer floodplain forests characterized by fast growing willows or maythorn shrubs will often be removed by tree felling in specific plots of this types of vegetation.

There are approximately 12.000 landowners in these floodplain areas, ranging from farmers (both crops and cattle grazing) to NGOs and private entities owning property in the floodplains. The challenge for the National Water Authority 'Rijkswaterstaat' is to focus efforts in the management of this vegetation in good dialogue with all these different owners, as they are responsible for timely management of vegetation on the land they own in line with legal requirements.

Present day monitoring of the floodplain vegetation is done via aerial photointerpretation and these maps are generated once per six years. These maps are translated into hydraulic roughness classes and used as input to the official hydraulic models for water level calculations to check on flood safety standards . The manual once per six-year update of the ecotope maps is costly and time consuming. There is a need for cost efficient up-to-date monitoring of vegetation. Remote sensing is a proven technology for large scale monitoring and has been tested in the past on Dutch floodplains but had not moved to an operational platform

\section{Aim of the research}

In this paper we present a new tool to monitor the floodplain vegetation in the Dutch part of the trained rivers Rhine and Meuse. The aim of this tool is to provide an easy screening method that helps focusing this effort, using classification of readily available satellite images in dominant vegetation types. The tool is the first-time satellite data is used for rivers in daily operations of the river manager. To develop a reliable tool, the following questions were asked:

How can the floodplain vegetation management process be aided by a monitoring tool?

What type of information and visualization will present results in a simple and effective way?

How to achieve robust and accurate classifications using up-to-date remote sensing data?

\section{Methods}

At the Dutch National Water Authority 'Rijkswaterstaat' (RWS) a dedicated workflow is followed to map and monitor the vegetation in the floodplains. Every 6 years the river system including the vegetation is mapped using aerial photographs and classified manually using a GIS-based approach . The manual photointerpretation map was further combined with information on the flood frequency and inundation depths, hydrodynamic forcing categories and information on the grazing intensity of specific parcels of land to yield an 'ecotope' map. An ecotope is a spatial unit relatively homogeneous in vegetation structure, succession stage and the main abiotic site factors that are relevant for plant growth . The ecotope map contains different classes of vegetation each assigned a dedicated hydraulic roughness value and is used in river flood management and associated hydraulic model calculations including the planning of vegetation management

To further aid vegetation management, communication and enforcement, a dedicated legal map of the allowable vegetation ("Legger") was created containing aggregated photointerpretation-based vegetation classes . This map is used to communicate with the approx. 12.000 landowners in the floodplain area (Figure 2) and depicts the legal limit for allowable vegetation (as a proxy for the allowable hydraulic roughness). The river authority's internal regulations stipulate that the floodplain vegetation should be in line with the legal vegetation map every October. The authority must report the status to the government before the winter, 
i.e. flood season, starts. Up to 2018 no good operational tool was available to objectively monitor the state of the vegetation in the floodplains on a more frequent basis than every 6 years. It was then when the need for an appropriate monitoring tool was defined that would allow a dedicated team at RWS to prioritize where in the floodplains field visits were needed to check if the current state of the vegetation is still in line with the legal vegetation map.

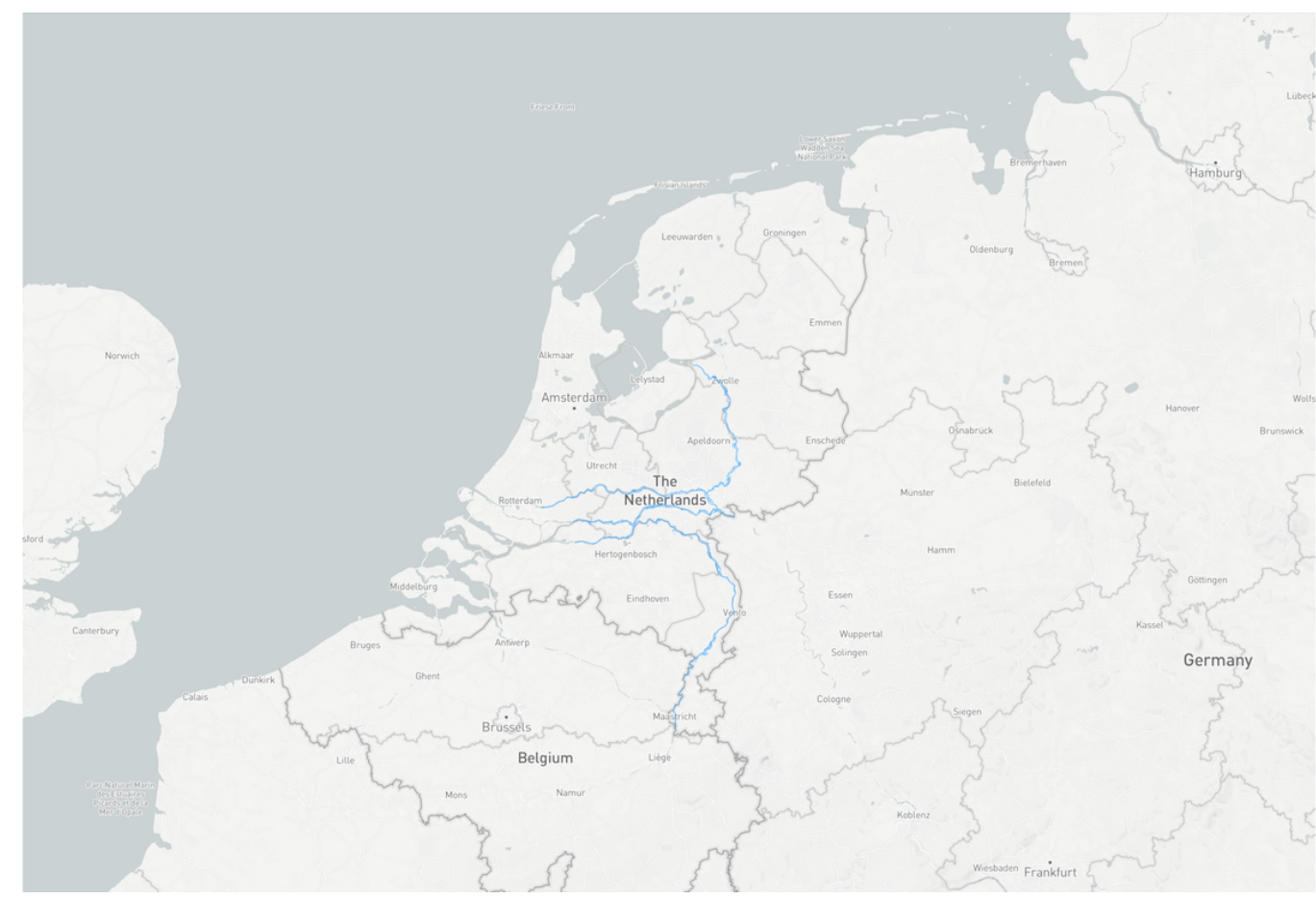

Figure 2: Rivers monitored and managed for vegetation shown in blue. Roughly $500 \mathrm{kms}$ of floodplains along the rivers Meuse and Dutch Rhine branches.

The terms of reference for a monitoring tool were defined in close cooperation with the end-users which in first instance consisted of the team responsible for floodplain vegetation management and the state forestry agency, one of the bigger landowners in the floodplains. We had ample discussion on the requirements of the end-users, such as 'the tool must be usable in the field e.g. using a tablet with GPS functioning', 'the tool must allow for quick analysis per cadastral plot' and 'information must be downloadable for further processing in GIS if needed'. The basic terms of reference were:

- Produce a floodplain vegetation map and show the difference to the legal permitted "state of the vegetation" of the whole river system;

- The map should be up to date, providing on the fly user selectable single-date maps;

- As a reference map for all users, a year-map should also be available;

- Use Sentinel-2 data and classify as robust and accurate as achievable;

- Use the legal vegetation map classes;

- Data and interface should be open and accessible for all stakeholders;

- Added in second instance: differentiate between field use (including GPS location) and desktop use; export of maps to GIS;

- Added in second instance: timeseries to visualize longer term trends.

The added value of year-maps was only later recognized as there was a need for a map with the highest 
possible accuracy that could be used in communication with all stakeholders, and would be less affected by inaccuracies in single image classifications as a result of e.g. atmospheric disturbances. The on-the-fly single date-maps gave a good up-to-date insight, but different stakeholders could confront each other with different day-maps. Also, for reference in communication, a more stable year-map was thus preferred. Also, time series were added to allow for a better understanding of the development of vegetation through the years and have a better approach for areas where changes in vegetation type fluctuated through the years, due to the management of the area.

The overall technical classification workflow is visualized in Figure 3. For data-retrieval, pre-processing and classification is carried out on the Google Earth Engine (GEE; Basic remotely sensed data consisted of Sentinel-2 MSI (Level-1C) data and the Dutch LiDAR based AHN (0.5m raw samples), both are available through GEE. Including Lidar-based data in the classification improves results for floodplain vegetation

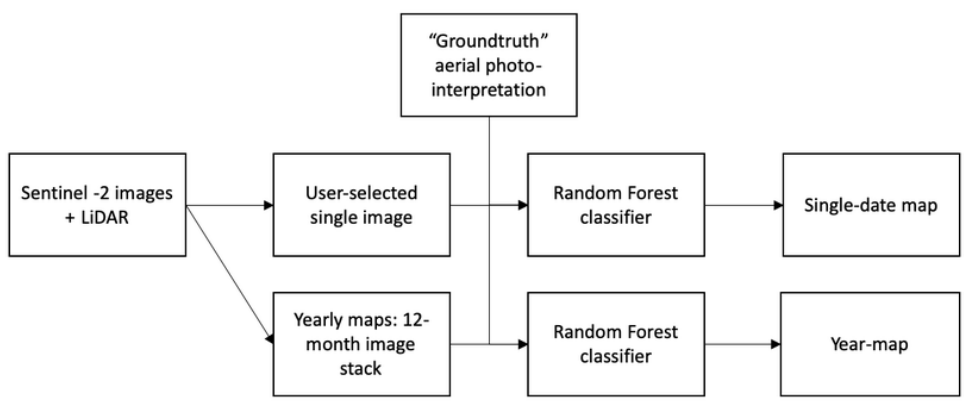

Figure 3: Workflow and end products. The basic data consists of Sentinel-2 images and LiDAR data, with two additional phenology-based bands in the year-map workflow. Ground truth is used for training and testing sets for the Random Forest classifier.

For ground truth the River Authority's photo-interpretation maps based on 2017 aerial images (false colour, $25 \mathrm{~cm}$ pixel resolution) were used which were remapped into the Legger-classes, see Table 1 . Training and test pixels were selected from patches (polygons) of the photo-interpretation maps . We excluded dynamic patches by comparing earlier photo-interpretation maps $(2017,2012,2006,1997)$ and selecting patches that remained stable over these years.

Table 1 Description and characteristic species (if applicable) of the used landcover classes (adapted from Harezlak et al., 2020; van Velzen et al., 2003).

\section{Landcover class Description/characteristic species}

Water

Several types of water bodies: river, side gullies, lakes 


\section{Landcover class Description/characteristic species}

Built \& Bare $\quad$ Buildings and roads Bare soil and soil with sparse vegetation (coverage by vegetation $<25 \%$ )

Fields and grass

Herbaceous

Shrubs

Arable land Grazed grass, characteristic species: Perennial ryegrass (Lolium perenne) and Meadow gra:

Forest

Characteristic species: Field eryngo (Eryngium campestre), Red fescue (Festuca rubra); Yarrow (Achill Characteristic species: Hawthorn (Crataegus monogyna and Crataegus laevigata), and young specimens Softwood forest, characteristic species: White willow (Salix alba), Crack willow (Salix fragilis); Black p

For the single-date maps we use a single Sentinel-2 image (bands: blue, green, red, NIR and SWIR) and add the raw LiDAR data as an additional input to the classifier. The year-maps are based on the same bands but include a stack computed from all the images in one year with a low cloud coverage. A classification on multi-temporal images of Sentinel-2 data is deemed more robust as this also captures changes over time .

Classified year maps are presently available for 2000-2019 in the viewer. For 2000-2011 Landsat-5 data are used, from 2013-2014 Landsat-8 data, and 2015-2019 Sentinel-2 data. We do not include classification for 2012 , as the data from Landsat-7 is affected by sensor failure. The full year image stack was created by building quarterly median images for the Landsat data, and monthly median images for Sentinel-2 data. This decision is based on image frequency for the region. Details on the Landsat classification method can be found at Harezlak et al. (2020). For each year in the Sentinel mission, the monthly medians yield an image with 12 times 5 bands (medians of blue, green, red, NIR and SWIR).

For classification we use the Random Forest classifier which is a robust classifier that (1) handles noisy and dissimilar data well and (2) discriminates reliably with mixed classes. As the day-maps were meant to be classified on-the-fly after user selection of a certain single Sentinel image, we optimised the classification time by the number pixels in the training and testing set and the number of trees in the random forest classifier (data not shown). Finally, we set the number of randomly selected pixels for each class to 200 ( $70 \%$ training, 30\% testing) and limited the number of trees to 6 . We tested classifying the Photo-Interpretation classes first and then aggregate to the Legger-classes versus classifying the Legger-classes directly, there was no difference in accuracy (data not shown). We opted for classifying the Legger-classes directly in the final product.

The post processing steps consisted of creating a change map and ranking and color-coding the changes to their relative change in hydraulic roughness. We used a green-yellow-red colour ramp. The largest decrease in hydraulic roughness (bush to water) was coded green, no change yellow, and highest increase in hydraulic roughness (water to bush) was coloured red.

The results are presented in an easy to use web-based map interface based Netlify and MapBox (Netlify, 2020; Mapbox, 2020) with a connection to GEE for data and computations. In this tool data layers are presented, and metrics are computed on-the-fly for relative vegetation cover per land ownership polygon. Classification results can also be downloaded for further analysis in a dedicated GIS.

\section{Results}

\section{The tool and main features}

The operational version of the vegetation monitoring tool can be found on https://vegetatiemonitor.netlify.com/\#/verken (in Dutch), best used in the Chromium or Google Chrome browsers. The main screen shows the satellite image layer, the legal vegetation map, the classified satellite image, and the comparison map, see Figure 4 and Table 2. The time-slider allows selecting 
pre-classified year maps or dates of sentinel-2 images that can be classified on the fly of any area of interest. Classifications can be downloaded in geotiff for GIS analysis.

After classification (day or year), a land cover pie chart of clicked upon individual cadastral polygons can be made and compared to the 'allowed' distribution. The sentinel-2 images available in the daily analysismode are updated every night with the most recently available images and allow for the inspection of the current situation (provided clouds do not cover the area of interest). In the top bar, users can switch to a lightweight field ('veld' in Dutch) version of the tool showing GPS location from smartphone or tablet to aid field visits.

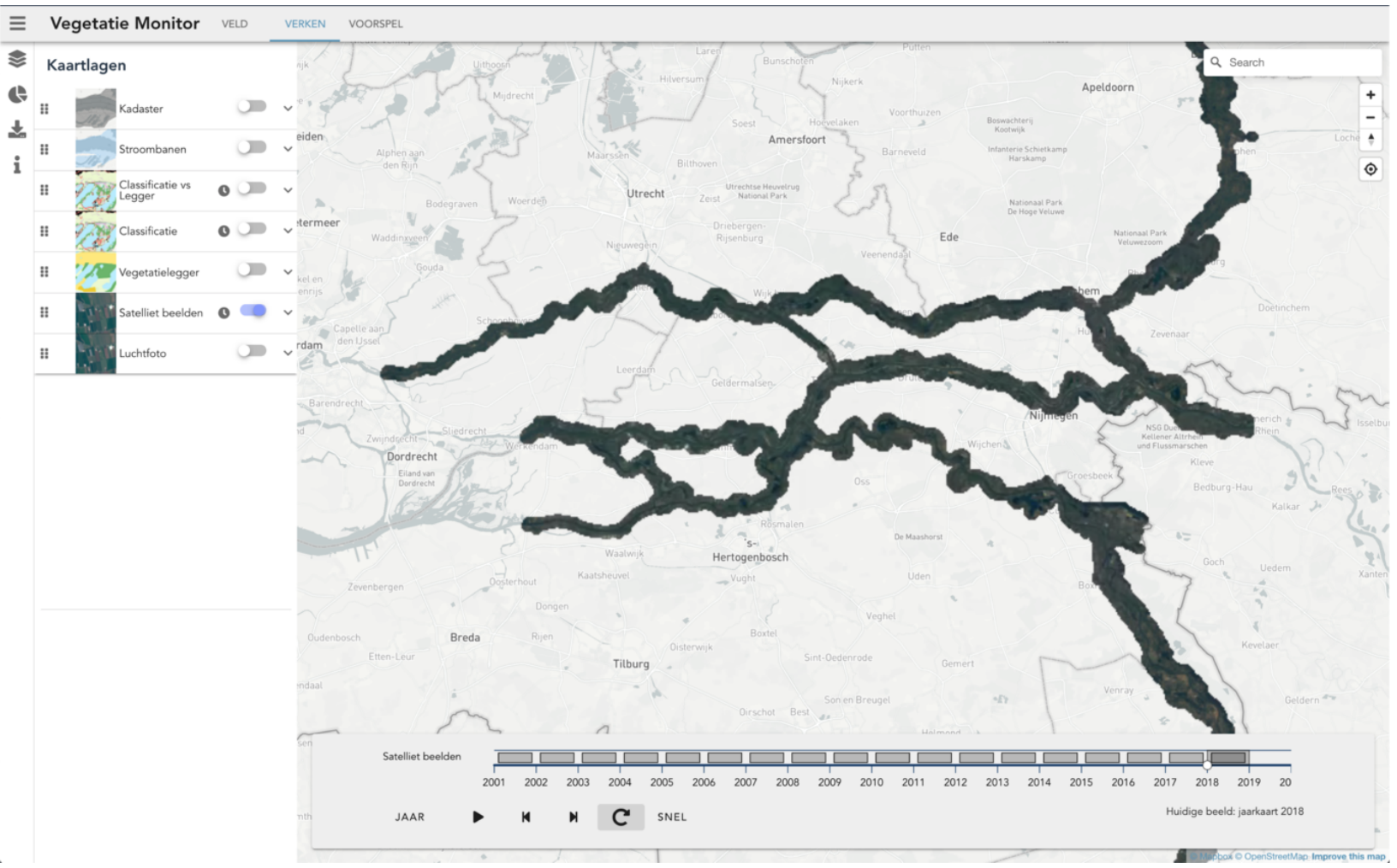

Figure 4: Front-end of the web-based vegetation monitor tool. Left to right: Layers, Metrics (pie-chart icon) and download menus. The main view is the map-layer menu ('kaartlagen') showing the layers (right), mapview and time-slider (bottom).

The layers of importance for the vegetation monitoring are summarized in Table 2. The cadastral map allows to identify the owners on whose land excessive vegetation is identified (for privacy reasons only the cadastral reference code is shown). The monitoring tool is meant to be a tool for quick identification and a start of the communication with landowners. The monitoring tool is open, so everyone with an interest in the floodplain vegetation can access and download the data.

Table 2 Overview of layers used

Map layers Description

Cadastral map

Flow path at flood levels ('Stroombanen' in Dutch)
Allows for analysis per cadastral plot to inform individual landowners Divides floodplains in flow paths and flowless areas. Hydraulic roughr 


\begin{tabular}{ll}
\hline Map layers & Description \\
\hline Classification vs. legal map & Gives color-coded information on the deviations from the legal map - \\
Classification & Shows the classification of the selected satellite image (both for daily \\
Legal vegetation map & Shows the reference legal map ('Legger' in Dutch). \\
Satellite image & Allows for visual inspection in RGB of the selected satellite image for \\
Aerial photograph & Allows for detailed visual comparison with the most recent available \\
\hline
\end{tabular}

\section{Classification and accuracies}

The tool has been tested in the field (using mobile phones and tablet) by end-users and found to be a suitable help in the assessment of the status of the vegetation. Accuracy of the year classification is currently in the order of $80 \%$ while overall accuracy of single image classifications vary between 60 and $70 \%$. A confusion matrix of the annual classification in the same year as the ground truth is shown in Table 3 . The confusion occurs especially between classes in which vegetation is very much alike, such as the confusion between willow shrub and willow forest, and between rough natural grass lands and production grasslands.

Table 3 Confusion matrix for the year-map (2017). The diagonal (bold values) show the number of accurately classified pixels. Rows depict the pixels assigned by classifier; columns are the distributions of the validation pixels over the classes. The value in the lower right cell is the overall accuracy.

\begin{tabular}{llllll}
\hline Water & Built \& Bare & Fields and grass & Herbaceous \& reed & Forest & Shrubs \\
\hline Water & $\mathbf{1 8}$ & 3 & 5 & 7 & 0 \\
Built \& Bare & 0 & $\mathbf{2 0 1}$ & 5 & 6 & 6 \\
Fields and grass & 0 & 6 & $\mathbf{1 8 8}$ & 9 & 3 \\
Herbaceous \& reed & 0 & 9 & 7 & $\mathbf{1 7 7}$ & 1 \\
Forest & 0 & 2 & 3 & 6 & $\mathbf{1 9 5}$ \\
Shrubs & 0 & 9 & 2 & 10 & 20 \\
$100 \%$ & $87 \%$ & $90 \%$ & $82 \%$ & $87 \%$ & $79 \%$ \\
\hline
\end{tabular}

A special case is confusion of water pixels with other land cover classes. As river water tables vary in time and the reference ground truth data does not, most water class errors seemed attributable to this. Figure 5 shows a day-classification result based on a single image. Clearly around some floodplain water bodies (in red circle) bare soil can be observed, when comparing these to the fixed legal map (Figure 6) this base soil comes out as change (red) because is it seen as water to 'build and bare' change. 


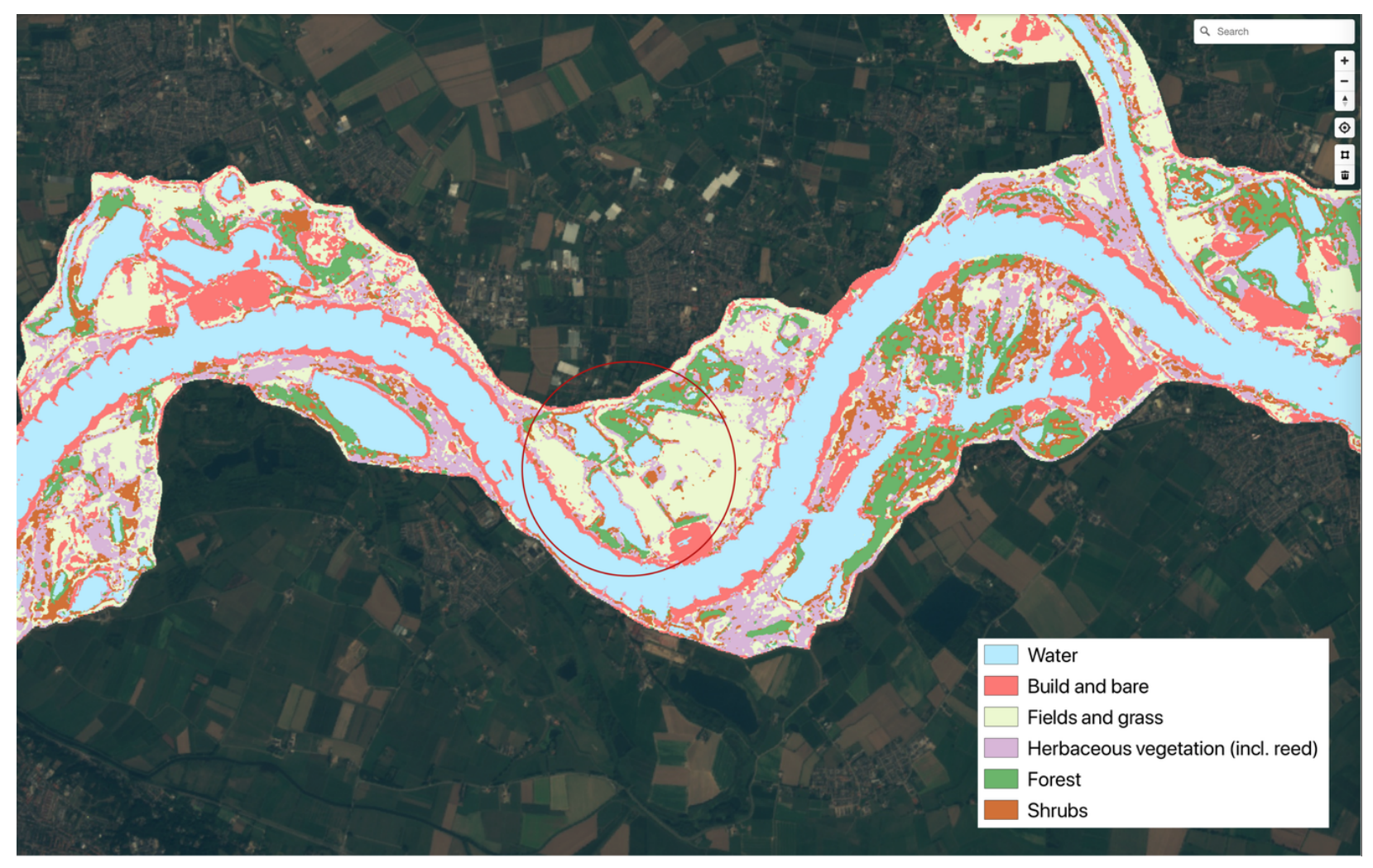

Figure 5: Example classification result of a single date on the fly classification (26-8-2019). 


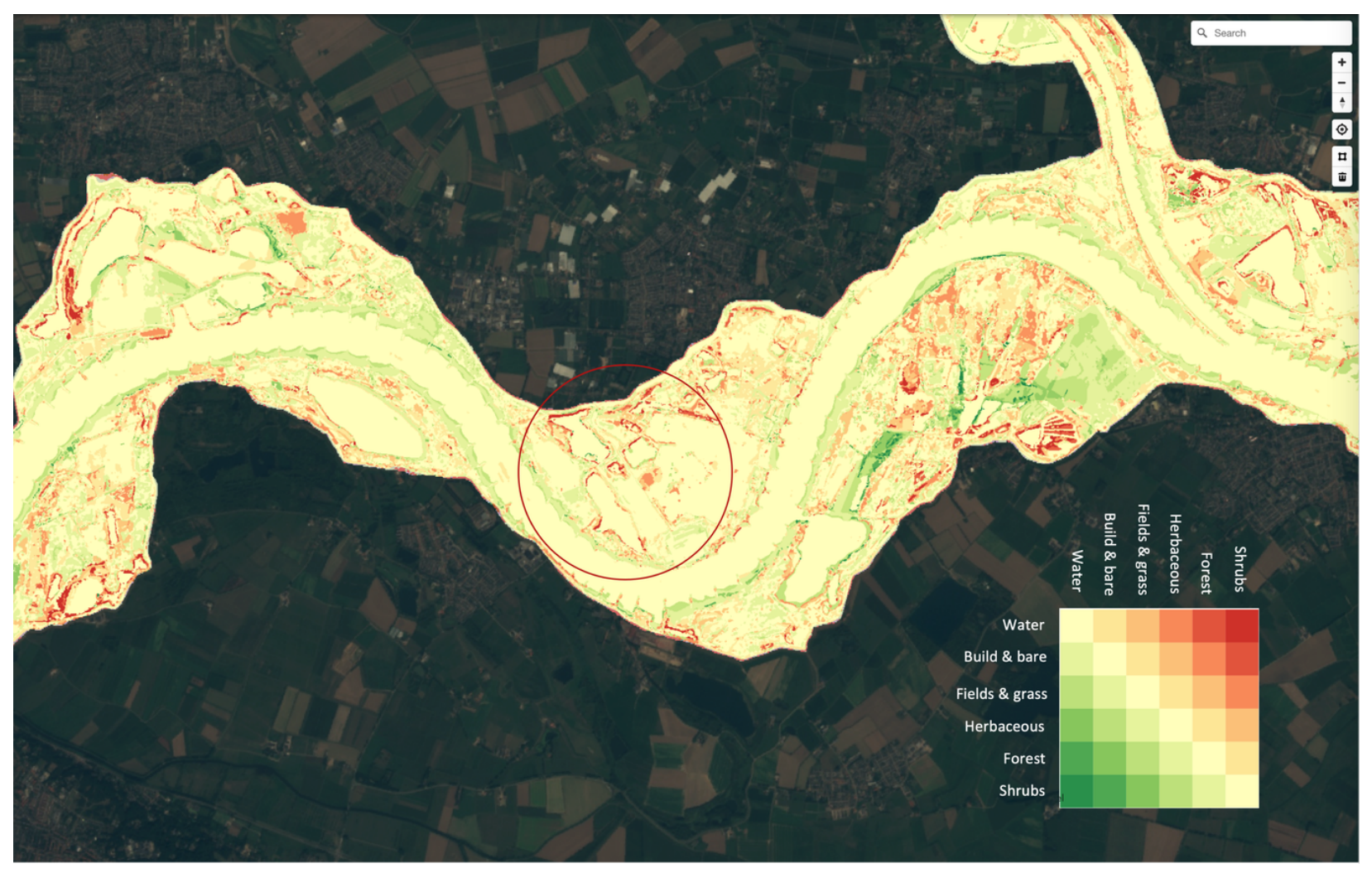

Figure 6: Example of difference map, comparing the classification with the legal map ('Legger'). The legend is color coded according the increase (red) or decrease (green) of hydraulic roughness of classified land cover in reference to the legal map ('Legger'). Around water bodies often 'false' changes related to fluctuating water tables can be observed, see water bodies in red circle (also previous figure).

\section{Monitoring changes}

Figure 7 shows an example of detected change on the cadastral level (surface area 2.3 ha.), a strong difference between the legal vegetation map and the current classification is shown by the red colors. In the legal map this plot is supposed to consist mainly of water, with some rough vegetation around the edges. Due to the natural process of vegetation development and a recent series of dry summers the pond has dried up and is overgrown with rough vegetation, consisting of a multitude of classes. The easy recognition of the red colors on the map, joint with the time series analysis and the information on the cadastral plot aids the dialogue with the landowner to clear the area. 

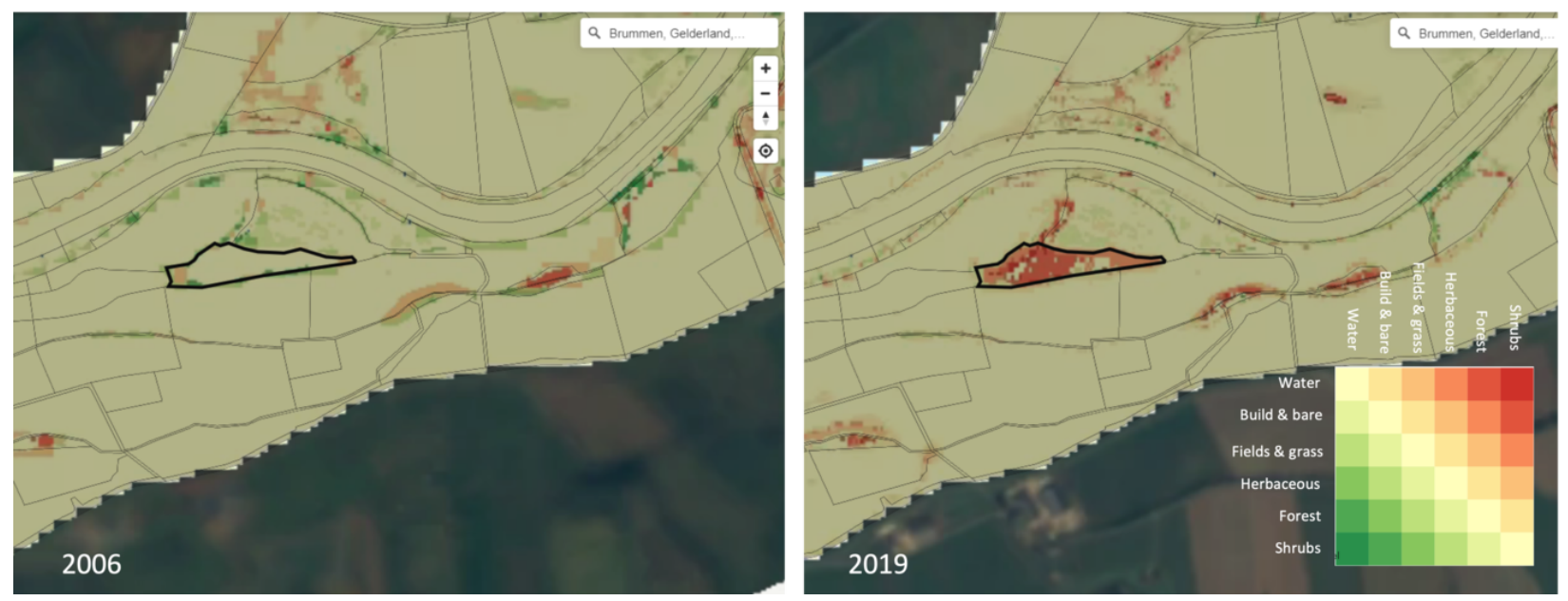

Figure 7: Two comparisons with the legal map with a cadastral polygon selected ( 2.3 ha., black line). Left situation in 2006 in compliance with the legal map. In 2019 a change to a more hydraulically rough state is observed (shades of red).

\section{Discussion}

\section{Operationalised advantages of satellite images}

Satellites have been used for many years to monitor changes, since the launch of the first LandSat satellite in 1984 developments have continued and now make available a vast amount of useable information. Many websites cater for quick access to processed data for various purposes, such as the aquamonitor, the forest watch on global scale (refs? Including the websites). However, the tool presented here is the first to be actually implemented for the Dutch River Authority (RWS) and to be used in the regulatory daily operational working process of river management. As far as we know this is also the first open access tool to present daily and automatically updating (Sentinel-2) satellite image analysis for floodplain management to a large group of end-users.

\section{Performance and implementation}

The accuracy of the tool is in line with earlier attempts for classifying floodplain vegetation in a similar number of classes and of the 'traditional' ecotope maps. The random forest classifier handles mixed classes such as 'fields \& grass' unexpectedly well proving its robustness . Incorporating more images in the classification improved the result as seen in the overall accuracy of year-maps and day-maps. Clearly, classes that are separable on difference trough time benefit from a temporal data. For example, fields are the type of class that has a specific seasonal signature being bare at the start of the growing season and harvested as dissimilar stages and dates.

We see some opportunities to improve the classification for year-maps and single-date maps. Separation of classes in year-maps showing a seasonal signal could be improved when incorporating pixel-level fitted parameters on sinusoidal function of yearly NDVI as bands. For single date (image) maps and year-maps, the inclusion of SAR data could provide some extra resolution . However, experiments with 'raw' Sentinel-1 data (hh, hv; data not shown) did not show significant improvement (order of about 1-2\% to total accuracy). Another approach could be a combination of segmentation in super-pixels and the use of texture within those super-pixels. This can also be a way to incorporate SAR data into the classification . However, for single date maps the classification speed determines the user-experience greatly. Therefore, there is a speed 
trade-off for incorporating new procedures and data in on-the-fly classification. The pre-classified year-maps do not have that disadvantage.

The accuracy was one of the most important topics in the discussion with the end-users. Beforehand we could estimate the accuracy based on quick scans and existing knowledge, but these numbers did not mean much to the end-users. During the first development year results were quickly shared and maps were used in the field. This experience helped translate the statistical accuracy in a form of trust in the produced maps. The vegetation-monitoring team could use the map in discussions with stakeholders and have no doubt about the map contents.

\section{Development process}

Developing a new monitoring tool for operational floodplain management is a process that is highly interactive and a strong dialogue with end-users is needed to create a useable tool. Features like GPS location indication for field use and downloadable images were implemented in a second iteration of the tool. Also, as the endusers started to download small AOIs (as in on-screen views) and mosaicking these in GIS, the download option evolved from downloads of single user selected classifications of the AOI in the viewer to downloads for total covered area. We further added the year-maps after different users asked for a "standard year map" to be able to refer to in reports and other stakeholders in order to standardize the yearly assessment of the vegetation state. It is foreseen that there will be additional changes to the tool out of the continued use and experience in the coming period. Also, a new or updated fixed map-layers will need to be included when made available. For instance, a new legal vegetation map will become available in 2020 .

The process of creating this tool has taken several years of intense discussions between researchers and managers at the national water board. The interplay between scientific and technical advances, and management requirements was helped by labelling this project as an innovative project within the framework of cooperation. The end-user interaction to come to the here presented tool must not be underestimated in the creation of an accepted and useful tool. The availability of Google Earth Engine with its continued up-to-date image library greatly speeded up and facilitated the prototyping and operationalizing of the project.

\section{Reflection on use and other applications}

The vegetation monitor is primarily designed as a quick and easy screening tool to identify those areas in the Dutch floodplains that in need of maintenance and is always used as a starting point for the dialogue with the responsible land owners and must be complimented with field visits for the final check on the correctness of the initial assessment. Next to this there are many potential possibilities to use the tool also in a wider context, for example to assess the impact of the changing lay-outs of vegetation distribution on flood water levels when these maps are directly used as input for the flood risk models. Also, the tool can easily be adapted to be useful in other river systems, providing that some ground truth data is available as test and training data. Several other initiatives are currently undergoing to classify the vegetation of the floodplains, but most often this is done in a GIS environment, making it less accessible to the general audience. Especially in large scale data-poor areas the technique may give a first order estimation of the current status and allow also for analysis on changes over time.

\section{Recommendations}

During the creation of the vegetation monitor there was discussion regarding the absolute accuracy of the individual classification results and which percentage of accuracy was deemed acceptable for the evaluation of the status of the vegetation. It took time to acknowledge that reaching $95 \%$ accuracy was not only technically not feasible, but also not necessary to give an overall judgement of the status of the vegetation. The annual maps with an average accuracy of between $80 \%$ and $86 \%$ are now being used and give a sufficient first indication of the situation. The communication that this tool is a first screening and that field visits will remain necessary in the final judgement has helped to accept that a certain level of inaccuracy is unavoidable. 
During the stakeholder process to define the terms of reference, it was clear that different types of users have different requirements. The stakeholder process is therefore very important in defining the final features of such tool.

The time series analysis feature has added benefit in judging a single classification, as it aids in checking for the consistency of the classification and potential fluctuations and dynamics through time, e.g. in relation to interannual fluctuations in river discharge and weather patterns and the response of vegetation to this.

\section{Conclusions}

Sentinel-2 (10m) based mapping aids small scale ( $>1$ ha) vegetation monitoring and management, even Landsat $(30 \mathrm{~m})$ is useful in small scale mapping of vegetation and changes herein. By using off the shelf images and methods 60-70\% accuracy was achieved for single images, while stacking year-round images yielded $86 \%$ accuracy. Accuracies of $60-70 \%$ are already good enough to inform, prioritize and decide in vegetation management. End-users need time to adjust and trust a new data-source, it's not only about the accuracy numbers. Inclusion of Google Earth Engine simplified building prototypes and an operational platform. Developing the tool in close cooperation with end-users helped to quickly identify unanticipated uses, useful features and facilitated trust in the tool.

\section{Data Availability Statement}

All used geodata from the river manager (aerial photographs and ground truth ecotope maps) is available for download and use .

The Google Earth Engine provided the remote sensing data, and all analysis tools and can be accessed at no cost for research .

\section{References}

Baptist, M. J., Penning, W. E., Duel, H., Smits, A. J. M., Geerling, G. W., van der Lee, G. E. M., \& van Alphen, J. S. L. (2004). Assessment of the effects of cyclic floodplain rejuvenation on flood levels and biodiversity along the Rhine river. River Research and Applications, 20(3). https://doi.org/10.1002/rra.778

Belgiu, M., \& Drăgu, L. (2016). Random forest in remote sensing: A review of applications and future directions. In ISPRS Journal of Photogrammetry and Remote Sensing (Vol. 114, pp. 24-31). Elsevier B.V. https://doi.org/10.1016/j.isprsjprs.2016.01.011

Breiman, L. (2001). Random forests. Machine Learning, 45(1), 5-32. https://doi.org/10.1023/A:1010933404324

Brown, E. C., Colstoun, D., Story, M. H., Thompson, C., Commisso, K., Smith, T. G., \& Irons, J. R. (2003). National Park vegetation mapping using multitemporal Landsat 7 data and a decision tree classifier. Remote Sensing of Environment, 85, 316-327. https://doi.org/10.1016/S0034-4257(03)00010-5

COHEN, W. B., \& GOWARD, S. N. (2004). Landsat's Role in Ecological Applications of Remote Sensing. BioScience, 54(6), 535. https://doi.org/10.1641/0006-3568(2004)054[0535:Irieao]2.0.co;2

Corcoran, J., Knight, J., \& Gallant, A. (2013). Influence of Multi-Source and Multi-Temporal Remotely Sensed and Ancillary Data on the Accuracy of Random Forest Classification of Wetlands in Northern Minnesota. Remote Sensing, 5(7), 3212-3238. https://doi.org/10.3390/rs5073212 
Corenblit, D., Tabacchi, E., Steiger, J., \& Gurnell, a. (2007). Reciprocal interactions and adjustments between fluvial landforms and vegetation dynamics in river corridors: A review of complementary approaches. Earth-Science Reviews, 84(1-2), 56-86. https://doi.org/10.1016/j.earscirev.2007.05.004

Csillik, O. (2017). Fast Segmentation and Classification of Very High Resolution Remote Sensing Data Using SLIC Superpixels. Remote Sensing, 9(3), 243. https://doi.org/10.3390/rs9030243

Donchyts, G., Baart, F., Winsemius, H., Gorelick, N., Kwadijk, J., \& van de Giesen, N. (2016). Earth's surface water change over the past 30 years. In Nature Climate Change (Vol. 6, Issue 9, pp. 810-813). Nature Publishing Group. https://doi.org/10.1038/nclimate3111

Gamba, P., \& Houshmand, B. (2002). Joint analysis of SAR , LIDAR and aerial imagery for simultaneous extraction of land cover , DTM and 3D shape of buildings *. International Journal of Remote Sensing, 23(20), 4439-4450. https://doi.org/10.1080/01431160110114952

Garofano-Gomez, V., Metz, M., Egger, G., Diaz-Redondo, M., Hortobagyi, B., Geerling, G., Corenblit, D., \& Steiger, J. (2017). Vegetation succession processes and luvial dynamics of a mobile temperate riparian ecosystem: The lower Allier River (France). Geomorphologie: Relief, Processus, Environnement, 23(3). https://doi.org/10.4000/geomorphologie.11805

Geerling, G., Labrador-Garcia, M., Clevers, J., Ragas, A., \& Smits, A. (2007). Classification of floodplain vegetation by data fusion of spectral (CASI) and LiDAR data. International Journal of Remote Sensing, 28(19), 4263-4284. https://doi.org/10.1080/01431160701241720

Geerling, G. W. G., Kater, E., van den Brink, C., Baptist, M. M. J., Ragas, a. M. J. A., \& Smits, a. J. M. A. (2008). Nature rehabilitation by floodplain excavation: The hydraulic effect of 16 years of sedimentation and vegetation succession along the Waal River, NL. Geomorphology, 99(1-4), 317-328. https://doi.org/10.1016/j.geomorph.2007.11.011

Geerling, G. W., Vreeken-Buijs, M. J., Jesse, P., Ragas, A. M. J., \& Smits, A. J. M. (2009). Mapping river floodplain ecotopes by segmentation of spectral (CASI) and structural (LiDAR) remote sensing data. River Research and Applications, 25(7), 795-813. https://doi.org/10.1002/rra.1181

Geerling, G. W., Vreeken-Buijs, M. J., Vreeken-Buijs, M., Jesse, P., Ragas, A., \& Smits, A. J. M. (2009). Mapping river floodplain ecotopes by segmentation of spectral (CASI) and structural (LiDAR) remote sensing data. River Research, 813(January), 795-813. https://doi.org/10.1002/rra

Gorelick, N., Hancher, M., Dixon, M., Ilyushchenko, S., Thau, D., \& Moore, R. (2017). Google Earth Engine: Planetary-scale geospatial analysis for everyone. Remote Sensing of Environment, 202, 18-27. https://doi.org/10.1016/j.rse.2017.06.031

Goward, S. N., Masek, J. G., Williams, D. L., Irons, J. R., \& Thompson, R. J. (2001). The Landsat 7 mission: Terrestrial research and applications for the 21st century. Remote Sensing of Environment, 78(1-2), 3-12. https://doi.org/10.1016/S0034-4257(01)00262-0

Harezlak, V., Geerling, G. W., Rogers, Ch. K., Penning, W. E., Augustijn, D. C. M., \& Hulscher, J. M. H. (2020). Revealing 35 years of landcover dynamics in floodplains of trained lowland rivers using satellite data. River Research and Applications, Submitted.

He, D. C., \& Wang, L. (1990). Texture Unit, Texture Spectrum, and Texture Analysis. IEEE Transactions on Geoscience and Remote Sensing, 28(4), 509-512. https://doi.org/10.1109/TGRS.1990.572934

Houkes, G. (2007). Ecotopenkartering Rijntakken-Oost 2005; Biologische monitoring zoete rijkswateren.

Klijn, F., \& Haes, H. A. U. de. (1994). A hierarchical approach to ecosystems and its implications for ecological land classification. Landscape Ecology, 9(2), 89-104.

Knotters, M., Brus, D., \& Heidema, A. (2008). Validatie van ecotopenkaarten van de rijkswateren. http://library.wur.nl/WebQuery/hydrotheek/lang/1872576 
Markham, B. L., Storey, J. C., Williams, D. L., \& Irons, J. R. (2004). Landsat sensor performance: History and current status. In IEEE Transactions on Geoscience and Remote Sensing (Vol. 42, Issue 12, pp. 26912694). https://doi.org/10.1109/TGRS.2004.840720

Marston, R. A., Girel, J., Pautou, G., Piegay, H., Bravard, P., \& Arneson, C. (1995). Channel metamorphosis, floodplain disturbance, and vegetation development: Ain River, France. Geomorphology, 13(1-4), 121-131. https://doi.org/10.1016/0169-555X(95)00066-E

Poortinga, A., Clinton, N., Saah, D., Cutter, P., Chishtie, F., Markert, K., Anderson, E., Troy, A., Fenn, M., Tran, L., Bean, B., Nguyen, Q., Bhandari, B., Johnson, G., \& Towashiraporn, P. (2018). An Operational Before-After-Control-Impact (BACI) Designed Platform for Vegetation Monitoring at Planetary Scale. Remote Sensing, 10(5), 760. https://doi.org/10.3390/rs10050760

Rijkswaterstaat. (n.d.). Geoservices geodata ecotope maps. Retrieved January 30, 2020, from https://www.rijkswaterstaat.nl/apps/geoservices/geodata/dmc/

Rijkswaterstaat. (2019). Leidraad Vegetatiebeheer Uiterwaarden 2019.

Rogan, J., Franklin, J., \& Roberts, D. A. (2002). A comparison of methods for monitoring multitemporal vegetation change using thematic mapper imagery. Remote Sensing of Environment, 80(1), 143-156. https://doi.org/10.1016/S0034-4257(01)00296-6

Straatsma, M., \& Baptist, M. (2008). Floodplain roughness parameterization using airborne laser scanning and spectral remote sensing. Remote Sensing of Environment, 112, 1062-1080. https://doi.org/10.1016/j.rse.2007.07.012

Straatsma, M., \& Middelkoop, H. (2006). Airborne laser scanning as a tool for lowland floodplain vegetation monitoring. Living Rivers: Trends and Challenges In, 87-103. https://doi.org/10.1007/s10750-005-1907-5

van der Molen, D. T., Geilen, N., Backx, J. J. G. M., Jansen, B. J. M., \& Wolfert, H. P. (2003). Water Ecotope Classification for integrated water management in the Netherlands. European Water Management Online (EWA).

van Iersel, W., Straatsma, M., Middelkoop, H., \& Addink, E. (2018). Multitemporal Classification of River Floodplain Vegetation Using Time Series of UAV Images. Remote Sensing, 10(7), 1144. https://doi.org/10.3390/rs10071144

van Oorschot, M., Kleinhans, M., Geerling, G., \& Middelkoop, H. (2016). Distinct patterns of interaction between vegetation and morphodynamics. Earth Surface Processes and Landforms, 41(6). https://doi.org/10.1002/esp.3864

van Oorschot, Mijke, Kleinhans, M., Buijse, T., Geerling, G., \& Middelkoop, H. (2018). Combined effects of climate change and dam construction on riverine ecosystems. Ecological Engineering, 120, 329344. https://doi.org/10.1016/j.ecoleng.2018.05.037

van Velzen, E., Jesse, P., Cornelissen, P., \& Coops, H. (2003). Stromingsweerstand vegetatie in uiterwaarden; deel I. Ministerie van Verkeer en Waterstaat, Directoraat-Generaal Rijkswaterstaat, RIZA Rijksinstituut voor Integraal Zoetwaterbeheer en Afvalwaterbehandeling. http://scholar.google.com/scholar?hl=en\&btnG=Search\&q=intitle:Stromingsweerstand + vegetatie + in + uiterwaarden $\# 0$

Warmink, J. J., Booij, M. J., van der Klis, H., \& Hulscher, S. J. M. H. (2013). Quantification of uncertainty in design water levels due to uncertain bed form roughness in the Dutch river Waal. Hydrological Processes, 27(11), 1646-1663. https://doi.org/10.1002/hyp.9319

Yan, E., Wang, G., Lin, H., Xia, C., \& Sun, H. (2015). Phenology-based classification of vegetation cover types in Northeast China using MODIS NDVI and EVI time series. International Journal of Remote Sensing, 36(2), 489-512. https://doi.org/10.1080/01431161.2014.999167 
Zhang, X., Wu, B., Ponce-Campos, G., Zhang, M., Chang, S., \& Tian, F. (2018). Mapping up-to-Date Paddy Rice Extent at $10 \mathrm{M}$ Resolution in China through the Integration of Optical and Synthetic Aperture Radar Images. Remote Sensing, 10(8), 1200. https://doi.org/10.3390/rs10081200

Data citations:

Google Earth Engine. (n.d.). Earth Engine Data Catalog . Retrieved January 30, 2020, from https://developers.google.com/earth-engine/datasets

Rijkswaterstaat. (n.d.). Geoservices geodata ecotope maps . Retrieved January 30, 2020, from https://www.rijkswaterstaat.nl/apps/geoservices/geodata/dmc/ 